\section{Palliative Care Ethics: a Good Companion}

Fiona Randall and R S Downie, United States, Oxford University Press, 1996, 195 pages, $£ 16.95$ pb, $£ 30$ hb.

Written jointly by a consultant in palliative medicine and a professor of moral philosophy, this book represents a profound treatise on many aspects of palliative care. The authors, modestly, call it a companion to conventional textbooks, but it is more than that. It calls into question many conventionally accepted assumptions, thereby posing some powerful challenges. Issues are raised in relation to information-giving, confidentiality, treatment decisions, team-work, research and other crucially important topics. The authors tackle many delicate concerns with professional and human integrity. The concluding section on resource allocation at macro- and micro-levels gives this work economic as well as professional credence. Whoever reads this book will be challenged to think. There will be points of agreement as well as disagreement between authors and readers. Thus, there is an abundance of extremely helpful material to stimulate informed debates.

As so aptly summed up in Dr Derek Doyle's foreword: palliative care will be the richer for the wisdom shared by the authors.

All who are in any way involved in palliative care, be it as health professionals, managers, economists or politicians, have a duty to read and discuss this important contribution to the literature.

LISBETH HOCKEY

Visiting Professor in Nursing Research, 1/2 Silverknowes Road, Edinburgh EH4 5NX

\section{The Moral Challenge of Alzheimer Disease}

\author{
Stephen G Post, Baltimore and \\ London, The Johns Hopkins \\ University Press, 1995, 142 pages, \\ $£ 25$.
}

This book provides a positive outlook on the moral status of people suffering from dementia. It challenges the assumption that dementia is necessarily associated with a lower quality and value of life. It provides an alternative position to the "hypercognitive" culture that places "excessively rationalistic" criteria for inclusion in the moral community, what Post calls "exclusionary ethics" which erode "love, care and solicitude". The guiding premise is "unconditional equality" based on the "incomparable human worth that everyone has as a human being".

The book begins with a series of narratives of people with dementia, focusing on the positive experience possible in dementia. Post relates the "autobiographical" story of Jan ("only lightly edited"), who, while suffering from dementia, finds meaning in snow flakes: "It had snowed and I had truly forgotten what a beautiful sight a soft, gentle snowfall could be. . . . As I bent down to gather a mass of those radiantly white flakes on my shovel, it seemed as though I could do nothing but marvel at their beauty. God had granted me the ability to see a snowfall through the same innocent eyes of the child I once was. . . . My husband says I am more content now than ever before!...".

Post addresses some of the ethical issues around caring, including the ethical issues around the self-sacrifice of carers and of behaviour control. The chapter entitled, "Fairhill guidelines on ethics and care of people with Alzheimer Disease" provides a consensus statement resulting from a community dialogue on the ethics of dementia care which took place between 1993-4, involving a wide variety of professionals involved in dementia care. A set of ideal standards of care are outlined for the following areas: truth-telling, disclosure of diagnosis, driving privileges, behaviour control, promoting autonomy and competence, evaluating quality of life, and death and dying.

There is a chapter on pre-symptomatic psychological and genetic testing. Post is concerned about the cultural forces driving such testing, rule by "genocrats" and moral problems in aborting fetuses found to be at risk of developing Alzheimer Disease.

In the following chapter, Post shows himself to be sympathetic to a sanctity, rather than a quality, of life doctrine. He opposes assisted suicide: "assisted suicide in the context of terminal illness ... must be placed in a communitarian context in which responsibilities for the common good . . . have moral importance. People with severe incurable illnesses have responsibilities to maintain the general cultural prohibition against suicide as a routine response to life's inevitable challenges." Rather, Post advocates "affirmative dementia care", and putting more money into dementia care. $\mathrm{He}$ asserts the "incompatibility hypothesis": legalisation of assisted suicide and euthanasia is incompatible with the development of adequate comfort care for the demented and dying. Since assisted suicide and euthanasia "save money", there would be pressure on the demented to die in "hard economic times". "Why invest in dementia care research, training, and facilities when assisted suicide or mercy killing are already available and much cheaper?" (This claim is liable to a reductio: why, we might ask, in hard economic times, would treatment for any condition be developed when there is a cheap and readily available alternative, that is, no treatment?) While Post does not present evidence for his conjectures, he asks us to remember the Jewish aphorism: "Start worrying. Letter to follow."

There is a strong Christian religious perspective throughout the book. Post claims that people have the right to request so-called futile interventions for religious reasons, citing approvingly the artificial ventilation of Helga Wanglie, an 86-year-old woman in a permanent vegetative state. Despite the desire of Mrs Wanglie's physicians to stop artificial ventilation, a judge reaffirmed Mr Wanglie's right to request this treatment. Mr Wanglie's reasons were that physicians should not play God, she would not be better off dead, that to withdraw life support would be moral decay and a miracle might occur. Post claims that such treatment is not futile: it worked because it "kept Mrs Wanglie breathing, warm to the touch, and excreting waste products".

Even in very advanced dementia, there is much that can be done, according to Post. This is a part of Post's "discourse ethics": "One act of discourse is the extension of the hand, another is the tone of voice that reassures the person. This is the sort of basic act that makes resurrection of a sort possible. ..".

This book may provide hope for people with dementia and their carers. As a reviewer, I found that my own position as a rationalist prevented me from connecting with this book. No doubt others will be more enthusiastic.

Post does make some true claims. For example, I agree that it can be justifiable to provide life-prolonging 